\title{
Judges and their emotions
}

\author{
TERry A MARONEY \\ Professor of Law, Professor of Medicine, Health, and Society, Vanderbilt \\ University, USA
}

$J$

udges are human beings; human beings have emotions; ergo, judges have emotions. The simplicity, even banality, of this syllogism belies its potentially revolutionary nature. In legal theory and popular opinion, the judge's humanity has long been either ignored or regarded as a necessary evil, an unfortunate consequence of having to populate the legal system with fallible, biased, real people. Emotion traditionally has been counted among the primary sources of fallibility and bias. The task of the legal system, under this view, is to systematically reduce the opportunities for judicial emotion to insert itself; the task of the good judge is to prevent emotion from exerting any influence wherever such opportunities remain.

Understood through the lens of these negative value judgments, the simple syllogism provides a rationale for vigilantly policing and suppressing judicial emotion. But what if those judgments were to change? If we were appropriately to value both the judge's humanity and the role of emotion in human life, the syllogism's implications would be profoundly different. We would seek not to police and suppress judicial emotion in all instances but, rather, to acknowledge, examine and sometimes even welcome it.

Revolutionary though it may be, this is the correct objective. The traditional devaluation of judicial emotion is both misguided and destructive.

As other contributors to this special issue have no doubt demonstrated, contemporary law and emotion studies have sought systematically to expose the assumptions about human emotion underlying legal theory and practice, and then to examine those assumptions in light of a sophisticated understanding of emotion itself. ${ }^{1}$ The aim of this short article is to show how applying that methodology compels a dramatic shift in how we think about judges and their emotions. I have explored these themes in a series of prior articles; ${ }^{2} \mathrm{I}$ synthesise them here. I first trace the development of the ideal of dispassionate judging and argue that it conflicts with virtually everything we know about emotion and its value. Having dislodged that ideal from its comfortable post, I suggest that the proper stance toward judicial emotion is not elimination but regulation. Judicial emotion regulation provides a flexible structure within which emotion may be examined, accepted, changed, or simply lived with. I then discuss the particular case of judicial anger. Anger can be either

1 Kathryn Abrams and Hila Keren, 'Who's Afraid of Law and the Emotions?' (2010) 94 Minn L Rev 1997.

2 Terry A Maroney, 'The Persistent Cultural Script of Judicial Dispassion' (2011) 99 Cal L Rev 629; Terry A Maroney, 'Emotional Regulation and Judicial Behavior' (2011) 99 Cal L Rev 1481; Terry A Maroney, 'Angry Judges’ (2012) 65 Vand L Rev 1207. 
helpful or unhelpful for judges, and therefore serves as an excellent testing ground on which to show how regulation helps to discern and enact that difference. I close with thoughts about directions for future research.

The project's centre of gravity is, at present, firmly in the USA. With the exception of some insights drawn from a study of Australian magistrates, the concrete examples on which I rely are from the US context. However, there is every reason to believe that the model I offer would translate well to the context of the British Isles. We share a common law heritage, including the traditional notion of dispassionate judging that long has animated that heritage. The psychological truths that challenge that traditional notion are, generally speaking, common to all human beings. Culture unquestionably influences how we experience and regulate emotion; legal and cultural differences (both between Britain and its former colonies, and among the countries of the contemporary British Isles) therefore deserve close analysis. ${ }^{3}$ Though such analysis is not possible here, I hope that this project will spur similar efforts in Ireland and the UK, where the study of law and emotion - let alone its applicability to judging - remains at a relatively young stage.

\section{Judicial dispassion: some history}

Insistence on emotionless judging is a cultural ideal of unusual longevity and potency. As long ago as the mid-1600s, none other than Thomas Hobbes declared that the ideal judge is 'divested of all fear, anger, hatred, love, and compassion'. ${ }^{4}$ More than three centuries later, US Supreme Court Justice Sonia Sotomayor testified at her confirmation hearing that judges 'apply law to facts. We don't apply feelings to facts. ${ }^{5}$ After a nasty public fight over whether Sotomayor might be unduly 'empathetic', a quality sought by US President Barack Obama, ${ }^{6}$ one journalist characterised the idea that emotion might influence judging as 'radioactive'. Then and now, calling a judge 'emotional' is considered a stinging insult. ${ }^{8}$

Several converging developments in Western culture and jurisprudence - here painted only in broad strokes - contributed to the remarkable entrenchment of the dispassionate judge ideal. It is rooted in the European Enlightenment's insistence on a dichotomy between emotion and reason. Sharply simplified, the Enlightenment intellectual tradition reified rational inquiry, science and secularisation. Emotion was associated with religious fervour, ignorance, prejudice, and reliance on epistemological sources such as tradition and revelation, forces from which enlightened persons sought to be freed. 9 This asserted dichotomy between reason and emotion became highly relevant to law. As law was aligned

3 See e.g. Batja Mesquita and Janxin Leu, 'The Cultural Psychology of Emotion' in Shinobu Kitayama and Dov Cohen (eds), Handbook of Cultural Psychology (Guilford Press 2007) 734-59. The fact that the US and the British Isles share a dominantly Western and anglophone cultural heritage suggests that cultural variation, while real, may be relatively limited. This will be progressively less so as the cultures become more separated by time, and as they become less internally homogenous.

4 Thomas Hobbes, Leviathan, A R Waller (ed) (CUP 1904/1651) 203.

5 <http://judiciary.senate.gov/hearings/testimony.cfm?id=3959\&wit_id=515> (statement of Judge Sonia Sotomayor).

6 Obama nomination remarks, quoted in John Hasnas, 'The Unseen Deserve Empathy Too' Wall Street Journal (New York, 29 May 2009); remarks of Barack Obama (Planned Parenthood Action Fund, 17 July 2007) $<$ http://lauraetch.googlepages.com/barackobamabeforeplannedparenthoodaction>; Susan A Bandes, 'Empathetic Judging and the Rule of Law' (2009) Cardozo L Rev De Novo 133.

7 Peter Baker, 'In Court Nominees: Is Obama Looking for Empathy by Another Name?' New York Times (New York, 26 April 2010) A12.

8 Jeffrey Rosen, 'Sentimental Journey: The Emotional Jurisprudence of Harry Blackmun' The New Republic (Washington, 2 May 1994) 13-14.

9 Henry Farnham May, The Enlightenment in America (OUP 1976) xiv, 42. 
with reason, it necessarily was positioned as emotion's opposite. This alignment only strengthened as law increasingly was conceptualised as a science. ${ }^{10}$

Interestingly, despite the Enlightenment tradition's commitment to intellectual and political equality, its position on emotion betrayed lingering elitism; emotion came to be associated with the irrational beliefs and unrestrained impulses of common people. ${ }^{11}$ Indeed, that association was on vivid display in the USA at the time of the nation's founding. ${ }^{12}$ In the well-known words of James Madison:

It is the reason, alone, of the public, that ought to control and regulate the government. The passions ought to be controlled and regulated by the government. ${ }^{13}$

Under this view - a point of agreement between Hobbes and Madison - judges were critical agents in ensuring that law acted as a bulwark against popular emotion. Judges fulfilled this responsibility by taming the emotions of litigants, ignoring those of the public, and divesting themselves of their own. ${ }^{14}$ Thus, by the turn of the twentieth century, it seemed clear that - in the words of a leading Continental theorist - emotionless judging was a 'fundamental tenet of Western jurisprudence'. ${ }^{15}$

Then came the legal Realists. As part of their effort to shatter illusions about law's objectivity and determinacy, Realists insisted that emotion formed part of a broader 'human element' that inevitably shaped judging. ${ }^{16}$ Benjamin Cardozo asserted that it was impossible to understand 'what judges really do' without dialogue on the contrast between 'reason versus emotion'. ${ }^{17}$ Jerome Frank went considerably further, drawing heavily on psychoanalytic theory to propose that judges routinely were led astray by 'childish' emotional drives and fantasies and should instead inspire to emotional 'maturity' (a state he left frustratingly undefined). ${ }^{18}$ Though their account of judicial emotion was simultaneously muddled and thin, the Realists contributed to a more general acknowledgment that judicial emotion exists and, contrary to the traditional party line, exerts influence. Indeed, during the tail end of the Realist heyday in the USA, one judge bluntly wrote that emotionless judges are 'mythical beings', like 'Santa Claus or Uncle Sam or Easter bunnies'. ${ }^{19}$

10 Christopher C Langdell, A Selection of Cases on the Law of Contracts (Little Brown \& Co 1871) vi.

11 May (n 9) 337.

12 Ibid 97-98.

13 The Federalist Papers 49 [James Madison], Clinton Rossiter (ed) (New American Library 1961) 317. See also Doni Gewirtzman, 'Our Founding Feelings' (2009) 43 U Rich L Rev 623, 637-40.

14 William J Brennan, 'Reason, Passion, and "The Progress of the Law" (1988) 10 Cardozo L Rev 3; Gewirtzman (n 13) 679; Richard A Posner, Frontiers of Legal Theory (Harvard University Press 2001) 226.

15 Karl Georg Wurzel, Methods of Juridical Thinking (1904), translated in Science of Legal Method: Selected Essays, Ernest Bruncken and Layton B Register (eds) (Boston Books 1917), 298. Wurzel wrote that it was necessary to neutralise judicial emotion because 'absence of emotion is a prerequisite of all scientific thinking' and judges regularly are 'exposed ... to emotional influences'.

16 Legal Realism was an intellectual movement anchored firmly in the USA, flourishing primarily between the First and Second World Wars. See e.g. Brian Leiter, Naturalizing Jurisprudence: Essays on American Legal Realism and Naturalism in Legal Philosophy (OUP 2007); Arthur L Corbin, 'The Law and the Judges' (1914) 3 Yale Rev 234; Charles Grove Haines, 'General Observations on the Effects of Personal, Political, and Economic Influences in the Decisions of Judges' (1922) 17 Ill L Rev 96 (1922); John Dickinson, 'Legal Rules: Their Function in the Process of Decision' (1931) 79 U Pa L Rev 833; Karl Llewellyn, 'Some Realism about Realism: Responding to Dean Pound' (1931) 44 Harv L Rev 1222.

17 Benjamin N Cardozo, 'Jurisprudence', Lecture before Assoc Bar City of NY, in Selected Writings of Benjamin Cardozo (Fallon Publications 1947) 7-46, 19

18 Jerome Frank, Law and the Modern Mind (Brentano's 1930) 143.

19 United States $v$ Ballard, 322 US 78, 93-94 (1944) (Jackson J dissenting). 
Despite this dose of realism, however, the ideal of dispassion has remained steadfast. ${ }^{20}$ For most, the sole point of acknowledging judicial emotion is to better control it. ${ }^{21}$ Thus, Justice Sotomayor successfully defended herself by testifying that judges are 'not robots [who] listen to evidence and don't have feelings. We have to recognise those feelings and put them aside. ${ }^{22}$ Realism may have modified the ideal but it did not fundamentally change its underlying premises.

\section{Why the ideal of dispassionate judging is misguided}

That the script of judicial dispassion is deeply ingrained does not make it correct. This has become increasingly clear as law has become more open to insights from other disciplines, and as those disciplines - particularly psychology - have greatly expanded our understanding of emotion. Emotion is not necessarily, or even usually, a pernicious influence in human life. Other contributors to this special issue no doubt have made a similar argument, and I therefore sketch it only briefly here. ${ }^{23}$ Contemporary affective psychology, with significant backing from philosophical accounts, teaches the following: emotion reveals reasons, motivates action in service of reasons, enables reason, and is educable. ${ }^{24}$

First, emotion reveals reasons because it relies on thoughts about states of the world. Every emotion contains an underlying belief structure, known in psychology as a cognitive appraisal. Fear, for example, reflects a cognitive appraisal that one faces 'an immediate, concrete, and overwhelming physical danger', while guilt attends self-evaluation of having 'transgressed a moral imperative'. ${ }^{25}$ The dichotomy between reason and emotion thus is revealed to be far less than sharp. Knowing what a person is feeling reveals what they are thinking, and both we and they can then evaluate those thoughts for accuracy and normative justification. Second, emotion motivates action in service of reasons, for it prompts us to respond to relevant states of the world in light of our goals. If a human being perceives that a bear is approaching, ${ }^{26}$ her fear focuses attention on the danger, prompts her to evaluate its personal relevance - for example, its incompatibility with her desire not to be mauled to death - and enables responsive action, including activating physical responses that promote survival (like fleeing or screaming for help). ${ }^{27}$ Third, emotion enables reason. Contemporary scientific research demonstrates the interdependence of emotional capacity and substantive rationality, particularly in the areas of practical reason, self-regarding choice,

20 For example, during the nomination battle over Justice Sotomayor, one US senator insisted that judicial empathy put 'nothing less than our liberty at stake' <http://judiciary.senate.gov/hearings/ testimony.cfm?id=3959\&wit_id=515> (statement of Senator Orrin Hatch).

21 Only a small minority of post-Realist judges and scholars have suggested that judicial emotion might be a good thing. See, e.g. Brennan (n 14); Irving J Kaufman, 'The Anatomy of Decisionmaking' (1984) 53 Fordham L $\operatorname{Rev} 1,16$.

2214 July 2009 <http://latimesblogs.latimes.com/washington/2009/07/sonia-sotomayor-hearingtranscript.html>.

23 A fuller account of contemporary research on emotion's nature and value may be found in Maroney (n 2) 'The Persistent Cultural Script' 642-52.

24 See, generally, Michael Lewis and Jeannette M Haviland-Jones (eds), Handbook of Emotions (2nd edn, Guilford Press 2000); Richard J Davidson et al (eds), Handbook of Affective Sciences (OUP 2003); Richard D Lane and Lynn Nadel (eds), Cognitive Neuroscience of Emotion (OUP 2000).

25 See, e.g. Richard S Lazarus, 'Universal Antecedents of the Emotions' in Paul Ekman and Richard J Davidson (eds), The Nature Of Emotion: Fundamental Questions (OUP 1994), 163, 164-5, table 1.

26 The approaching bear scenario is one that has been commonly invoked in emotion theory since the inception of the field: William James, 'What is an Emotion?’ (1884) 9 Mind 188-205, 190.

27 These propensities toward typified physical responses are called 'action readiness' or 'action tendencies'. See David Sander and Klaus R Scherer (eds), The Oxford Companion to Emotion and the Affective Sciences (OUP 2009) $1-2$. 
and social judgment. ${ }^{28}$ Moral judgment, too, appears to be strongly intertwined with emotional capacity. ${ }^{29}$ Finally, emotion is educable; not only can humans alter its external manifestation (for example, by suppressing or forcing a smile), but the emotion itself can be altered by changing one's underlying thoughts and goals. ${ }^{30}$ As Richard Lazarus nicely explained, though evolved 'biological universals link the if with the then' - as where perception of irrevocable loss leads to sadness - individual and cultural factors 'affect the if 'by determining what circumstances are thought to constitute such a state of affairs. ${ }^{31}$ In addition to explaining human emotional diversity, this flexibility creates space for emotional growth and change.

Taken together, these findings show that the traditional legal story casting emotion as stubbornly irrational is simply not true. These lessons about emotion are as true for judges as for other humans. Literal elimination of judicial emotion is not just unrealistic as a goal; 32 it is destructive as a value. The inquiry therefore must shift, asking not how judges can be rid of emotion but rather how they can cope with it - and potentially derive something of value from it.

\section{Judicial emotion regulation}

As the prior discussion makes clear, under both the traditional account of judging and its post-Realist iteration we expect judges to regulate emotion, either by preventing its emergence or by walling off its influence. The presumed object of such efforts is to attain an emotionless state when performing a judicial function. Taking emotion research seriously requires us to abandon a rigid commitment to that object. It does not, however, require us to abandon a commitment to emotion regulation. On the contrary, it counsels us more fully to embrace emotion regulation as a critical judicial skill.

Emotion regulation refers to any attempt to influence what emotions we have, when we have them, and how those emotions are experienced or expressed. ${ }^{33}$ It is difficult to overstate regulation's importance. Recognising that emotion is of enormous value does not signify that it must be allowed free rein. ${ }^{34}$ Emotion often helps us achieve our goals, such as escaping bear maulings, but this is not always the case. Fear sometimes can paralyse; sadness can overwhelm; love can blind. Emotion can reveal undesirable thoughts, as when

28 The best-known of these studies (which continue to proliferate) are by Antonio Damasio, Antoine Bechara and their collaborators. See, generally, Antonio R Damasio, Descartes' Error: Emotion, Reason, and the Human Brain (Grosset/Putnam 1994); Antonio Damasio, The Feeling of What Happens: Body and Emotion in the Making of Consciousness (Harvest Books 1999); Antoine Bechara et al, 'Characterization of the Decision-making Deficits of Patients with Ventromedial Prefrontal Cortex Lesions' (2000) 123 Brain 2189-202. See also S W Anderson et al, 'Impairments of Emotion and Real-world Complex Behavior following Childhood - or Adultonset Damage to Ventromedial Prefrontal Cortex' (2006) 12 J Int Neuropsychol Soc 224, 224; Terry A Maroney, 'Emotional Competence, "Rational Understanding”, and the Criminal Defendant' (2006) 43 Am Crim L Rev 1375, 1392-97.

29 Walter Sinnott-Armstrong (ed), Moral Psychology: The Neuroscience of Morality: Emotion, Brain Disorders, and Development, vol 3 (MIT Press 2008); Dacher Keltner et al, 'Emotions as Moral Intuitions' in Joseph P Forgas (ed), Affect in Social Thinking and Behavior (Psychology Press 2006) 162-75; Jesse Prinz, 'The Emotional Basis of Moral Judgments' (2006) 9 Phil Explorations 29; <www.wjh.harvard.edu/ jgreene/> (Moral Cognition Lab); Liane Young et al, 'Damage to Ventromedial Prefrontal Cortex Impairs Judgment of Harmful Intent' (2010) 65 Neuron 845-51.

30 James J Gross and Ross A Thompson, 'Emotional Regulation: Conceptual Foundations' in James J Gross (ed), Handbook of Emotion Regulation (Guilford Press 2007) 3-24, 13-15.

31 Lazarus (n 25) 167-8.

32 In the prior articles I have demonstrated at length why the ideal is unrealistic, by systematically culling evidence of judicial emotion including (inter alia) sadness, joy, anger and fear.

33 James J Gross, 'Antecedent- and Response-Focused Emotion Regulation: Divergent Consequences for Experience, Expression, and Physiology' (1998) 74 J of Personality and Soc Psychol 224.

34 Jennifer S Beer and Michael V Lombardo, 'Insights into Emotion Regulation from Neuropsychology' in Gross (n 30). 
one feels jealousy rather than pride at a child's achievement, or unworthy goals, as when one delights in the misfortune of others. At times it is important to show one's emotions - for example, by smiling proudly at the child - while at others just the opposite is called for for example, by feigning courage to dissuade a possible assailant. Emotion is adaptive, but so too is the capacity to regulate it in response to varied environmental demands and in service of accurate beliefs and worthy objectives. ${ }^{35}$ Such capacity is a hallmark of what is popularly known as 'emotional intelligence'. ${ }^{36}$ Indeed, Aristotle's vision of the virtuous man - one who has the right emotions, in the right situation, for the right reasons, and to the right degree ${ }^{37}$ - is now a philosophical and psychological article of faith.

Judges in their private lives, of course, can strive for such emotional virtue. Far more important for legal theorists, though, is the realisation that judges can do so in their professional lives as well. Thanks to the pioneering work of the US sociologist Arlie Hochschild, we may recognise this effort as a form of emotional labour, or the work of regulating emotion so as to conform to the expectations of one's profession and workplace. ${ }^{38}$ Though empirical research is scant, all indications are that judges do perform such emotional labour. Surveyed Australian magistrates, for example, reported expending significant energy coping with emotional challenges. One described his caseload as a constant parade of 'absolute misery'; another spoke of having difficulty at the end of the day 'walking away and erasing everything about everything I've heard about families and the stress that they're under, [and] the treatment children have been dished out'. ${ }^{39}$ Importantly, these and other judges ${ }^{40}$ find this emotional labour difficult. Much of that difficulty stems from two intertwined causes. The first is the unrealistic expectation of dispassion. US state court judges complained that because the legal system tends 'to strip away emotions', they were becoming 'insulated and numb'. ${ }^{41}$ The second is the lack of available models. As one Australian magistrate put it bluntly:

[T] here's two things that can happen to you. Either you're going to remain a decent person and become terribly upset by it all because your emotions . . . are being pricked by all of this constantly or you're going to ... grow a skin on you as thick as a rhino, in which case I believe you're going to become an inadequate judicial officer because once you lose the ... feeling for humanity you can't ... do the job. ${ }^{42}$

35 Vanderkerckhove et al, 'Regulating Emotions: Culture, Social Necessity, and Biological Inheritance' in Marie Vanderkerckhove et al (eds), Regulating Emotions: Culture, Social Necessity, and Biological Inheritance (Blackwell 2008), 1-12, p 3 (regulation serves to 'fine-tune' our emotional system to 'socio-cultural contexts'); Richard J Davidson et al, 'Neural Bases of Emotion Regulation in Nonhuman Primates and Humans' in Gross (n 30), 47-68, 47 (regulation provides 'important flexibility to our behavioral repertoire').

36 Daniel Goleman, Emotional Intelligence: Why it Can Matter More than IQ (Bloomsbury 1996); Paula M Niedenthal et al (eds), Psychology of Emotion: Interpersonal, Experiential, and Cognitive Approaches (Psychology Press 2006) 162.

37 James R Averill, Anger and Aggression: An Essay on Emotion (Springer-Verlag 1982) (quoting Aristotle, 'Nicomachean Ethics' (1106b20) in R McKeon (ed), The Basic Works of Aristotle (Random House 1941).

38 Arlie R Hochschild, The Managed Heart: Commercialization of Human Feeling (University of California Press 1983); see also Vanda L Zammuner and Cristina Galli, "The Relationship with Patients: "Emotional Labor" and its Correlates in Hospital Employees' in C E J Hartel et al (eds), Emotions in Organizational Behavior (Psychology Press 2004) 254, 251-83.

39 Australian norms, like those of the USA, dictate that judges 'not be swayed' by emotion and deem any emotionally influenced judicial action 'irrational': Sharon Roach Anleu and Kathy Mack, 'Magistrates' Everyday Work and Emotional Labour' (2005) 32(4) Journal of Law and Society 590.

40 See also Mary Lay Schuster and Amy Propen, 'Degrees of Emotion: Judicial Responses to Victim Impact Statements' (2010) 6 Law, Culture and Humanities 75 (reporting similar findings among judges in Minnesota).

41 Ibid 89.

42 Anleu and Mack (n 39) 612. 
As this cri de coeur suggests, we have stranded our judges. Not only have we tethered them to an unrealistic goal, but we have commanded them to carry out a highly sophisticated psychological task with no guidance as to how. I already have offered a solution to the first problem, which is to abandon pretensions of dispassion. The solution to the second problem is nowhere near as straightforward. Fortunately, we have an excellent guide - a robust, well-validated body of contemporary psychological research on emotion regulation. ${ }^{43}$

As I have elaborated at greater length elsewhere, applying this body of research to the judging context yields a promising model for judicial emotion regulation, one that encourages judges to engage with their emotions rather than avoid, suppress, or deny them. I cannot do full justice to that model here, but I will outline its fundamentals.

Emotion regulation may be pursued by way of a diverse array of strategies, all designed to change either the emotion-eliciting situation, one's thoughts about that situation, or one's responses to that situation. ${ }^{44}$ Each strategy has distinct costs, benefits and effects on decision-making. ${ }^{45}$ All have both occasional utility and maladaptive manifestations, the latter of which may include causing paradoxical or unintended effects. ${ }^{46}$ Simplistic ideas about emotion tend to lead to simplistic regulatory choices, which often will prove a poor fit with a complicated reality. ${ }^{47}$ Poor regulatory choices can be remarkably impervious to correction through experience. Finally, the most critical regulatory capacity is flexibility. ${ }^{48}$

A sound model for judicial emotion regulation identifies relatively stable attributes of judging that render particular strategies generally more or less well suited to that context and prioritises those with greatest inherent flexibility. That model indicates the following about the major categories of regulatory strategy, presented here in descending order from the most promising to the most maladaptive.

The most promising judicial emotion regulation strategy is cognitive reappraisal. Reappraisal involves changing one's thoughts in order to feel a desired emotion or avoid an undesired one. Imagine fear upon seeing a snake. To reappraise that fear requires a change in one's perception (it's actually a curvy stick), evaluative judgment (that type of snake is harmless), or goal (I don't value my physical safety). So, for example, a judge may decide to think about a neglectful parent not as a person who is trying to harm her child, but rather as someone who is not presently equipped to handle parenting. That mental shift might spur compassion (rather than, say, disgust or anger) and focus the judge on a new goal, such as determining whether and how the legal system could help the parent do better. Cognitive reappraisal can also help judges achieve relative emotional neutrality. Experiments have consistently shown that people asked to view disturbing images 'with the detached interest of a medical professional' and to 'think about them objectively and analytically rather than

43 James J Gross, 'Preface' in Gross (n 30) xi-xiv and figure P1; Sander L Koole, 'The Psychology of Emotion Regulation: An Integrative Review' (2009) 23 Cognition and Emotion 4, 5.

44 Gross and Thompson (n 30) 10. Another common strategy is to alter one's subjective and physical state with drugs and alcohol. Josh M Cisler et al, 'Emotion Regulation and the Anxiety Disorders: An Integrative Review' (2010) 32 J Psychopathology and Behav Assessment 68, 75. Because this tactic is so obviously off-limits to on-duty judges, I do not discuss it.

45 Renata M Heilman et al, 'Emotion Regulation and Decision Making Under Risk and Uncertainty' (2010) 10 Emotion 257.

46 See, e.g. <http://selfcontrol.psych.lsa.umich.edu/>; Gross (n 33) 224; Koole (n 43) 6.

47 Tanja Wranik et al, 'Intelligent Emotion Regulation: Is Knowledge Power?' in Gross (n 30) 393-407, 400, 403; Koole (n 43) 22.

48 Nancy Eisenberg et al, 'Effortful Control and its Socioemotional Consequences' in Gross (n 30) 287-306, 290; James J Gross, 'Emotion Regulation: Affective, Cognitive, and Social Consequences' (2002) 39 Psychophysiology 281, 289. 
as personally, or in any way emotionally relevant' feel and display fewer emotions than control subjects. ${ }^{49}$ Such reappraisal has virtually no costs; indeed, it appears to enhance memory. Adopting such a professional attitude is a form of cognitive pre-commitment that changes how the mind processes stimuli. To a doctor, a wound becomes less disgusting than informational; focusing on its informational value for diagnosis and treatment allows the doctor to bypass any disgust reaction. Similarly, judges can learn to treat vivid stimuli as professionally relevant rather than personally provocative.

Reappraisal is the strategy that most closely conforms to our present expectations of judges. However, to be effective consistently and over the long term it must be acknowledged, trained, and practised. Further, such reappraisal cannot always be relied upon, for judges will encounter situations that cause even the most practised professionalism to crack. Consider a recent video posted on YouTube of a judge screaming angrily at a mother accused of child neglect. Interviewed afterwards, he confessed, 'I reacted humanly; I try not to do that. ${ }^{50}$

Another strategy that often will be highly adaptive for judges is disclosure. Disclosure usually takes the form of talking or writing about one's emotions and the experiences that prompted them. As highly stigmatised as judicial emotion disclosure is, judges might be expected to do this privately (with family and friends) if at all. Even such private disclosure is likely to be productive: though thinking and talking about emotions does not generally lessen their intensity, it enhances self-knowledge, allowing judges to build 'a specific and detailed data bank' about their emotions from which they can draw lessons. ${ }^{51}$ Disclosure also draws others into that evaluative process and, over time, helps one live with emotion more comfortably. However, private disclosure is unlikely to be sufficient. Sharing emotional challenges with other judges would be particularly beneficial, strengthening camaraderie and facilitating mutual support. ${ }^{52}$ After all, who could have more insight than another judge? Unfortunately, peer disclosure appears rare. One prominent judge told me that he had never had such a discussion with judicial colleagues and did not think they would be open to such conversation. Another US federal judge wrote that he had once broached the subject of the emotional difficulty of criminal sentencing with a senior colleague, only to receive a vague assurance that it would 'get easier'. ${ }^{53}$ Loosening the expectation of dispassion would make peer disclosure more likely, as judges would be less worried about harming their reputations by admitting emotional reactions.

Public disclosure may also be beneficial. Though it is rare, judges occasionally publicly acknowledge emotion: both of the previously mentioned judges wrote articles doing so, ${ }^{54}$ and judges occasionally let emotion show in written opinions, often in dissent. Public disclosure has many potential benefits. It would normalise judicial emotion and draw the broader community into the emotion-evaluation process. However, some caution is warranted. As discussed in the section to follow, disclosure's benefits are likely to vary

49 J P Hayes et al, 'Staying Cool when Things Get Hot: Emotion Regulation Modulates Neural Mechanisms of Memory Encoding (2011) 4 Frontiers in Human Neuroscience 1-10; Jane M Richards and James J Gross, 'Emotion Regulation and Memory: The Cognitive Costs of Keeping One's Cool' (2000) 79 Journal of Personality and Social Psychology 410.

50 Maroney, 'Angry Judges' (n 2).

51 Pierre Philippot, Aurore Neumann and Nathalie Vrielynck, 'Emotion Information Processing and Affect Regulation: Specificity Matters!' in Marie Vanderkerckhove et al (eds), Regulating Emotions (Blackwell 2008) 202, 206.

52 Bernard Rimé, 'Interpersonal Emotion Regulation' in Gross (n 30), 474 and table 23.1.

53 Mark W Bennett, 'Heartstrings or Heartburn: A Federal Judge's Musings On Defendants' Right and Rite of Allocution' (2011) (March) The Champion 26, n 1.

54 Alex Kozinski, 'Teetering on the High Wire' (1997) 68 U Colo L Rev 1217. 
considerably depending on the judge's objectives, the manner in which it is done, and the emotion at issue; expressions of anger, disgust and contempt may be uniquely dangerous.

A strategy that is often necessary, but highly costly, is behavioural suppression. Behavioural suppression involves inhibition of expressive behaviour, such as facial expression (e.g. smiling), verbalisation (e.g. groaning), or bodily movement (e.g. cringing). Physical impassivity is generally what we expect of judges. That expectation is not entirely irrational, for it serves at least two important purposes. A judge who projects little emotional responsivity models good courtroom decorum, which others may mimic. ${ }^{55}$ Such a judge also blocks others from perceiving her appraisals. Imagine a judge who believes that a witness is shading the truth, but knows that a jury, not she, is entrusted with making the credibility determination. The judge needs to mask any anger, disgust, or contempt, lest the jury see (and presumably rely upon) what it broadcasts about the judge's opinion of the witness. Unfortunately, though, behavioural suppression is effortful and comes at a cost. Suppression consumes cognitive resources, impairing memory and one's ability to engage in logical reasoning. ${ }^{56}$ As one prominent contemporary scholar of emotion regulation summed it up, behavioural suppression makes a person temporarily 'stupider'. ${ }^{57}$ Nor do these costs tend to pay off in terms of directly changing emotion. Not only does behavioural suppression not lessen the intensity of negative emotion, it may magnify physiological responses. ${ }^{58}$ Adopting a 'poker face' thus is beneficial only where it serves some critical judicial function, such as maintaining order; it is not a steady state toward which judges always should aspire.

Judges have limited ability to engage in another common strategy: situation selection and modification. Situation selection involves choosing or avoiding situations because of their anticipated emotional effect; modification refers to altering the situation's features. An example of judicial situation selection would be to choose the court in which one serves. A judge might avoid the family court if she believes that exposure to distressed families will be depressing, or seek appointment to the probate court if she believes that she will feel pride in helping grieving families settle their affairs. Such self-selection might be beneficial if the judge's predictions are accurate - and there is reason to believe they may not be, unless preceded by experience; a judge seeking to transfer out of the family court, for example, is on better footing in this regard than one seeking to avoid it. But few judges have such a luxury, and many serve in courts of general jurisdiction in any event. Judges may also try to exert control over the cases they hear. This strategy is likely to be even less possible. Judges can recuse themselves from cases only for specific reasons, such as when it implicates a personal interest; avoiding emotion is not one of those reasons. ${ }^{59}$ Few courts have discretionary jurisdiction, and even those that do - like the US Supreme Court - cannot forever avoid deciding certain issues. But if a judge generally cannot avoid emotional situations, she might be able to modify them. For example, she might schedule gruesome evidentiary testimony on a day that will permit frequent breaks, or delegate aggravating tasks - such as interacting with

55 Anleu and Mack (n 39) 614.

56 Barnaby D Dunn et al, 'The Consequences of Effortful Emotion Regulation when Processing Distressing Material: A Comparison of Suppression and Acceptance' (2009) 47 Behavior Res and Therapy 761, 764 n 2; R Baumeister et al, 'Ego Depletion: Is the Active Self a Limited Resource?’ (1998) 74 J Personality and Social Psychol 1252; Jane M Richards and James J Gross, 'Personality and Emotional Memory: How Regulating Emotion Impairs Memory for Emotional Events’ (2006) 40 J Res in Personality 631.

57 Conversation of Terry A Maroney with James J Gross (5 March 2010).

58 James J Gross and R W Levenson, 'Emotional Suppression: Physiology, Self-report, and Expressive Behavior' (1993) 64 J Personality and Social Psychol 970-86.

59 Only rarely, when a judge's emotional reaction to a party rises to the level of threatening fundamental fairness, will recusal be appropriate: Liteky v US, 510 US 540, 555-56 (1994). 
obnoxious attorneys on scheduling issues - to a clerk. It is reasonable to assume that judges routinely make such small accommodations, with little impact on the quality of judging. However, courtroom management responsibilities may foreclose many modifications. The judge may not, for example, decline to set scheduling orders with bothersome attorneys. Nor may she walk out of the courtroom to take a break whenever she wants one, particularly if she has a busy docket or is sitting on a judicial panel. ${ }^{60}$ Further, judges often must face emotionally vivid stimuli so as to control the extent to which others are exposed to it. For example, if the judge must decide whether the jury should be permitted to view a gruesome autopsy photo, she must look closely at the photo herself. Avoiding and altering emotionally vivid situations therefore is only of limited use to judges.

Attentional deployment and distraction are closely related to avoidance and modification, but take place internally: one modifies emotional response by refusing to attend to the provocative stimulus. Instead, one looks at or thinks about something else, reads, hums a song, and so on. This approach will virtually never be appropriate. It is not hard to see why: if we expect anything of our judges, it is to pay attention to all relevant aspects of a case, including the unpleasant ones. For similar reasons, mindfulness is not obviously compatible with judging. Drawn from the Buddhist tradition, mindfulness emphasises observation and acceptance of mental phenomena, including emotion. ${ }^{61}$ At the risk of oversimplification, its explicitly nonjudgmental approach might conflict with the task of a judge - that is, to judge. To be sure, attentional deployment, distraction, and mindfulness might all have some place in the judge's regulatory toolbox. Sometimes the judge will have the luxury (say, in chambers) of taking a mental break by playing sudoku; she might be able to introduce calming music, or glance at a picture of her family; and the precepts of mindfulness might help her judge herself less harshly if she is not always able to manage her emotions exactly as she would like.

Finally, seeking directly to suppress emotional experience is always likely to be maladaptive for judges, despite the fact that it is encouraged by the ideal of dispassion. Suppression can take various forms: 'steeling oneself', as when one resolves in advance simply not to feel any emotion in response to an anticipated stimulus; denial, as when one pretends that an emotion never existed or that it has been extinguished; and literal repression, described by Freud as a process by which unwanted emotional memories are displaced to the subconscious. Experiential suppression is a bad bet for a variety of reasons, the first being that it seldom works. Emotions cannot easily be headed off at the pass just by willing them to be so. ${ }^{62}$ This is particularly true for judges, who cannot help but encounter novel, often extreme, situations for which they find themselves unprepared. ${ }^{63}$ Moreover, experiential suppression, like its behavioural counterpart, comes at a high cost. It impairs logic, selfcontrol and social judgment. ${ }^{64}$ Pushing emotions out of mind also can result in ironic increase in their intensity, particularly when under stress or cognitive load (as judges usually

60 One judge told me that he did sometimes simply walk out so he could pull himself together; however, he was the sole judge in a small, rural jurisdiction and had virtually total control over his courtroom. Maroney, 'Emotional Regulation' (n 2) 1525.

61 Koole (n 43) 27.

62 Richard Chambers, Eleonora Gullone and Nicholas B Allen, 'Mindful Emotion Regulation: An Integrative Review' (2009) 29 Clinical Psychol Rev 560, 566; Koole (n 43) 6 ('people may still display unwanted emotions despite their best efforts').

63 See, e.g. In re Skyler M, 2007 WL 2109797 (Cal App 2 Dist) ('All my years of sitting here, I don’t think I've ever seen a doctor cry on the witness stand.').

64 Daniel M Wegner, White Bears and Other Unwanted Thoughts: Suppression, Obsession, and the Psychology of Mental Control (Guildford Press 1989) 81-82; Iris B Mauss, Silvia A Bunge and James J Gross, 'Culture and Automatic Emotion Regulation' in Vandekerckhove et al (n 51). 
are). ${ }^{65}$ Emotional suppression can harden into a repressive coping style, associated with poor health outcomes ${ }^{66}$ and arrogance. ${ }^{67}$ The former is relevant to judges primarily as people (though it raises the prospect of longevity costs), but the latter clearly is of great concern for judges qua judges.

In sum, judicial emotion is best regulated not by turning away from it, but rather by turning toward it. The ideal of judicial dispassion encourages overconfidence in the ability of judges to eliminate emotion by willing themselves not to feel it, denying that they do, and controlling its outward expression. ${ }^{68}$ Judicial emotion suppression is the sort of maladaptive regulatory cycle that resists self-correction, particularly since it is societally reinforced. Instead, we ought to encourage judges to prepare realistically for inevitable emotional challenges, process and respond thoughtfully to any emotions they may have, and selectively integrate those emotions into their decisional processes. The ideal of the dispassionate judge thus might be replaced by that of the emotionally well-regulated judge.

\section{Judicial anger: an illustrative example}

To be successful, a new model for thinking about judicial emotion must be both theoretically sound and functional on the applied level. I therefore will briefly demonstrate how it may be applied to judicial anger. ${ }^{69}$ Anger is a fitting focus, for it is both one of the most common judicial emotions and the one judges feel most free to express. Written opinions, news reports, new media sources such as YouTube, and judges' self-reports amply demonstrate the ubiquity of anger. Lawyers are the most common targets, followed by litigants (including criminal defendants), witnesses, and other judges. The most common triggers for judicial anger are incompetence (particularly on the part of lawyers), disrespect, unwarranted harm inflicted on others, and lying.

Anger is quintessentially judicial. ${ }^{70}$ It follows assessment that a rational agent has committed an unwarranted wrongdoing, either because she intended to harm or was neglectful where care was warranted. ${ }^{71}$ Once triggered, anger both generates a desire to affix blame and assign punishment and facilitates actions necessary to carry out that desire. From this perspective it is hard to see how judges could fail to feel anger, or how they could do without it, given the rather precise match between its core attributes and much of what we ask judges to do. Certainly, judges might be able to render many decisions in a cold, clinical manner and reach equivalent outcomes. ${ }^{72}$ But if valuing the judges' humanity means anything - if we retain a strong intuition that we would choose a judge over a decisiongenerating robot - it means retaining a capacity for righteous anger. A judge ought to care about her work and the affected persons. If she does, it would be impossible for her to feel

65 Wegner (n 64) 122-24; George Loewenstein, 'Affect Regulation and Affective Forecasting' in Gross (n 30) 180-203, 190-91; Niedenthal et al (n 36) 176.

66 Chambers et al (n 62) 564.

67 Koole (n 43) 20.

68 Wegner (n 64) 15. Overconfidence discourages self-examination and learning. See e.g. Stuart Oskamp, 'Overconfidence in Case-study Judgments' in Daniel Kahneman et al (eds), Judgment under Uncertainty: Heuristics and Biases (CUP 1982) 287-93.

69 A far more extended treatment, including a detailed description of specific episodes of judicial anger, may be found in Maroney, 'Angry Judges' (n 2).

70 Indeed, in many religious traditions deities are thought of as righteously angry judges. Michael Potegal and Raymond W Novaco, 'A Brief History of Anger', in Michael Potegal et al (eds), International Handbook of Anger (Springer 2010) 9-24.

71 James R Averill, Anger and Aggression: An Essay on Emotion (Springer-Verlag 1982) 248-49.

72 This was Seneca's position, but it is one that has few adherents. Seneca, De Ira (Loeb Classical Library AD 40-50/1963). 
nothing when determining that a fellow human has raped a child, cheated a pensioner, violated a direct order to produce vital documents, lied under oath and so on. As Robert $\mathrm{C}$ Solomon put it, we cannot have a sense of justice without the capacity and willingness to be personally outraged'. ${ }^{73}$

But anger seems also to pose a danger to neutral, careful decision-making, a quality as valued in a judge as a sense of justice. ${ }^{74}$ Anger tends to trigger relatively shallow patterns of thought, increasing reliance on heuristics and stereotypes. It can lead to premature decisions, as the angry person tends to be very certain of her judgment and may resist new or conflicting evidence; it also has been shown to increase punitive, perhaps even disproportionately punitive, actions. Anger triggered by one cause can easily bleed over into unrelated contexts. Finally, it can manifest itself in aggression and violence. Each of these characteristics is deeply threatening to competent judicial performance.

Judicial anger must therefore be carefully regulated. Because it is so common, the US courts have developed a rough template for its post hoc assessment. Some judicial anger is considered right and proper (for example, being 'appropriately angered' by a defendant who made false accusations of government misconduct in order to waste resources); ${ }^{75}$ most is thought to fall within an unfortunate but understandable buffer zone (including 'expressions of impatience, dissatisfaction, annoyance, and even anger, that are within the bounds of what imperfect men and women, even after having been confirmed as federal judges, sometimes display'); ${ }^{76}$ and a small slice is deemed improper, because it bespeaks bias, ${ }^{77}$ prompts carelessness or haste, ${ }^{78}$ suggests a poor judicial temperament, ${ }^{79}$ or demonstrates unfitness to serve. ${ }^{80}$ These hindsight categories are functional enough, though they have a 'we-know-it-when-we-see-it' quality. But what is most needed is a system for shaping judicial anger experience and expression in the first instance. Emotion regulation serves that function.

First, if the judge knows she is going to encounter an angering situation - such as a criminal sentencing of a defiant and 'reprehensible' person - she can prepare realistically by acknowledging that he is going to make her angry and choosing a response pattern in advance. She may think carefully about her professional role, which - she may decide - includes expressing anger on behalf of the public and any victims, making victims feel welcome, and denying the defendant the satisfaction of having 'gotten to' her. If those are her goals, she may decide to maintain a poker face while the defendant speaks, treat victims with warm courtesy, and read prepared remarks so she can control exactly how she communicates anger. Executing such a plan will be easier the more accurately the judge predicts how the hearing is likely to unfold. Judge Mark Bennett, for example, consistently encounters infuriatingly insincere nonsense from sophisticated, highly educated white collar defendants' ${ }^{81}$ Experience with such recurrent triggers helps the judge formulate realistic anger regulation plans.

73 Robert C Solomon, A Passion for Justice: Emotions and the Origins of the Social Contract (Addison-Wesley 1990) 34, 42.

74 For a thorough review of anger's behavior effects, see Paul M Litvak, 'Fuel in the Fire: How Anger Impacts Judgment and Decision-Making' in Potegal et al (n 70); Jennifer S Lerner and Larissa Z Tiedens, 'Portrait of the Angry Decision Maker: How Appraisal Tendencies Shape Anger's Influence on Cognition’ (2006) 19 J Behav Dec Making 115, 117.

75 Campbell v US, 2010 WL 1379992 (SD West Virginia, 10 March 2010).

76 Liteky v US, 510 US 540, 555-6 (1994).

77 Harrison v Anderson, 300 F Supp 2d 690 (SD Indiana 2004).

78 Sentis Group v Shell Oil, 559 F 3d 888 (8th Cir 2009).

79 McBryde v Committee to Review Circuit Council Conduct and Disability Orders of Judicial Conference of US, 264 F 3d 52, 54-55 (DC 2001).

80 In re Sloop, 946 So 2d 1046, 1051, 1053, 1057 (Fla 2007) (per curiam).

81 Bennett (n 53) 26. 
Life being unpredictable, these plans will not always pan out. One defendant surprised his judge by spitting in her face; 82 another mocked the judge; 83 another lobbed extremely profane insults. ${ }^{84}$ Judges therefore need a plan to cope with anger that could not be (or simply was not) avoided. Cognitive reappraisal is critical here as well. It can help judges discern (a) what their anger is about, and whether it (b) rests on an accurate assessment of reality, (c) reflects proper judicial values, and (d) can or should be rethought. For example, if a judge reacts angrily because a litigant appears to be violating an order to sit down, she could consider the possibility that the litigant is simply confused. ${ }^{85}$ If she is angry at an attorney who announces that he has prevailed against her on appeal, she may remind herself that he had a right to appeal and that the legal system depends on her acceptance of such judgments. ${ }^{86}$

Reappraisal requires self-awareness, which is beneficial for other reasons as well. A judge who is both self-aware and aware of the common effects of anger will be in a far better position to regulate her behaviour. She will be in a better position to suppress angry behaviours when appropriate. If she feels like she has a short fuse on a given day, she may be more careful than usual in asking herself if she is truly angry at this person for this incident, or whether anger is being displaced. A judge who sees herself precipitously declaring the proceedings 'done' and imposing the harshest possible sanction might realise that she needs to take a minute (or more) to gather herself before finalising any decisions. ${ }^{87}$

Self-awareness is also furthered through productive disclosure. By discussing their feelings with trusted others and peers, judges can enlist support in recognising what tends to make them angry, how they tend to act, and how anger has helped or hindered their judging. Public disclosure can help as well. When Judge Gregory O’Brien Jr wrote an article discussing the causes of his frequent anger and how he learned to overcome it, it represented an important step in lessening that anger and lengthening his career - and it helped the public to better understand the challenges judges face. ${ }^{88}$

In contrast, seeking to suppress or deny anger is a dangerous path. Judges have been removed from the bench for so aggressively trying to tamp down anger that they blow up in extreme and unpredictable ways. ${ }^{89}$ The health risks of emotion suppression are particularly severe for this emotion, and the callous arrogance that suppression breeds is of special concern given judges' extraordinary power over people's lives.

Here, a special note of caution is warranted: that anger suppression is bad does not signify that unfettered anger disclosure is good. Making anger known can be destructive in a way that showing other emotions, like sadness, generally cannot. Consider the Wisconsin judge who publicly referred to his colleague as a 'total bitch', 90 or the federal judge who stunned the audience at an oral argument by accusing a colleague of hogging time and

82 'How to Piss Off the Judge' (13 August 2009) < www.youtube.com/watch?v=uCNo4ky6GXE>.

83 'Judge, Defendant Spar During Sentencing' (Associated Press, 24 March $<$ www.youtube.com/watch?v=X7Z4LQO6B58>.

84 Mary Lay Schuster and Amy Propen, 'Degrees of Emotion: Judicial Responses to Victim Impact Statements' (2010) 6 Law, Culture and Humanities 75, at 93.

85 <http://wn.com/Judge_loses_it_on_cam,_jails_man_for_sitting_too_slow $>$.

86 Anderson v Sheppard, 856 F 2d 741 (6th Cir 1988).

87 Sentis Group v Shell Oil, 559 F 3d 888 (8th Cir 2009).

88 Gregory C O’Brien Jr, 'Confessions of an Angry Judge' (2004) 87 Judicature 251, 252.

89 In re Sloop, 946 So 2d 1046, 1051, 1053, 1057 (Fla 2007) (per curiam).

90 'Justices' Feud gets Physical' Milwaukee-Wisconsin Journal Sentinel (Milwaukee, 25 June 2011). 
suggesting that he leave the courtroom. ${ }^{91}$ Anger also appears to be distinct from many other emotions in that giving it voice can increase its potency. ${ }^{92}$ Judges can come to enjoy the sense of power, confidence, and control anger brings. The case law is replete with judges who repeatedly belittle, abuse, insult, humiliate and lash out at litigants, attorneys and even colleagues, and these incidents are typically infused with great anger. These dangers highlight the great importance of cultivating judicial anger-management skills.

In short, competent anger regulation will help a judge prepare realistically for anger, for it is certain to come; respond thoughtfully to anger, for she may be able to rethink the situation or select a different response; and integrate anger selectively, by making use of it when it is helpful to do so and by finding other outlets - such as private disclosure to a trusted colleague - when it is not.

\section{Conclusion: toward a new ideal of emotionally intelligent judging}

This article has briefly set forth the fundamental flaws in the ideal of judicial dispassion, made the case that judges are best advised to engage with rather than suppress their emotions, and demonstrated how taking such an approach can maximise beneficial iterations of judicial anger while minimising destructive ones.

Unfortunately, neither law schools nor judicial institutes routinely address these issues, let alone provide the necessary training; this appears to be as true in the British Isles as in the USA. The US medical profession, facing a strikingly similar challenge, has begun to do so, with uniformly positive results. Though the research remains preliminary, it seems that more emotionally intelligent doctors are not only happier, more well-adjusted people, but better doctors as well.93 One highly promising move would be to develop a parallel approach for judicial education. A comparative approach might also yield important insights. Particularly in the Continental system, judges are more coherently trained than in the US and in the British Isles, where judges train as lawyers and are either appointed or elected straight out of practice. The career-track model of judging therefore may provide more natural opportunities for training. It is also worth considering whether cultural differences might reliably track differences in judicial emotion and its regulation. In addition to pilot work that has begun in Australia, ${ }^{94}$ a research duo has just begun to undertake an ambitious project to observe and analyse judges' emotions in Sweden. Were such studies to both proliferate and coordinate, the potential would be enormous.

Judicial emotion is truly terra nova for legal scholars, psychologists, sociologists, and so many others. One hopes that more brave judges will step forward to share their experience and help us navigate this terrain. Let's go.

91 Debra Cassens Weiss, '5th Circuit Oral Arguments Turn Contentious when Chief Judge Tells Colleague to Shut Up' ABA Journal (Chicago 26 September 2011). It is highly likely that expression of certain other emotions, certainly contempt and probably disgust, has equally destructive potential. See Maroney, 'Angry Judges' (n 2).

92 B J Bushman, 'Does Venting Anger Feed or Extinguish the Flame? Catharsis, Rumination, Distraction, Anger, and Aggressive Responding' (2002) 28 Personality and Social Psychol Bull 724-31.

93 Jason M Satterfield and Ellen Hughes, 'Emotional Skills Training for Medical Students: A Systematic Review' (2007) 41 Med Educ 935; Daisy Grewal and Heather A Davidson, 'Emotional Intelligence and Graduate Medical Education' (2008) 300 J Am Med Association 1200, 1200-02; Kant Patel, 'Physicians for the 21st Century: Challenges Facing Medical Education in the United States' (1999) 22 Evaluation and the Health Profs 379-98; Stacey Teicher Khadaroo, 'Medical School Reinvented: Adding Lessons in Compassion' Christian Science Monitor (Boston, 15 September 2009) USA 2; L Granek, 'When Doctors Grieve’ New York Times (New York, 27 May 2012) SR122.

94 Anleu and Mack (n 39). 